\title{
Neonatal and infantile fistulas: spectrum of findings on conventional contrast imaging with surgical correlation
}

\author{
Mohammed Zaki ${ }^{i *}$ and Mohamed Y. Batikhe
}

\begin{abstract}
Background: Neonatal and infantile fistulas are diverse and include many types. Conventional contrast images are used to delineate the fistulous tracts. The aim of this study is to illustrate the conventional radiological spectrum of neonatal and infantile fistula with surgical correlation.

Methods: Neonates and infants with suspected fistulas were included in this study. The patients may be presented by cutaneous fistula with discharge, profuse oral secretion and cyanosis on feeding, or imperforate anus. After full clinical data were taken, plain X-ray, contrast imaging, and abdominal sonography were done to the patients. Treatment was tailored according to the case.

Results: Our study included 34 patients ( 25 boys and 9 girls): one case of branchial fistula; 2 cases with thyroglossal fistula; 10 cases of tracheo-esophageal, esophago-cutaneous, and esophago-pleural fistulas; 3 cases with vitello-intestinal fistula; one case with urachal fistula; 12 cases with recto-urinary, recto-vaginal, and recto-perineal fistula; 4 cases with peri-anal fistulas; and finally one case with iatrogenic urethra-cutaneous fistula. Radiological findings were well correlated with the surgical data.
\end{abstract}

Conclusion: Many types of neonatal and infantile fistulas were shown in this series including tracheoesophageal, recto-urinary, and other neonatal fistulas. Radiological and surgical data were well matched.

Keywords: Neonatal and infantile fistulas, Fistulogram, Fistulectomy

\section{Background}

Neonatal and infantile fistulas are not so rare identity to be encountered. Many types of neonatal and infantile fistulas are illustrated in the literature. Fistulas associated with ano-rectal malformation and tracheo-esophageal atresia are the most famous ones [1,2]. However, there are also many other variants of neonatal and infantile fistula. Omphalo-mesenteric, iatrogenic, and urachal fistulas are also seen. There are very rare types observed and reported in the literature such as gastrocolic and vascular fistula [3-5].

\footnotetext{
* Correspondence: zakifm2000@yahoo.com

'Department of Radiology, Sohag Faculty of Medicine, Sohag University,

Sohag, Egypt

Full list of author information is available at the end of the article
}

Neonates with fistula may be presented very early by profuse oral discharge and signs of suffocation in esophageal atresia and non-passage of meconium such as ano-rectal malformations. Also, it may be presented late such as umbilical or cutaneous discharge in iatrogenic or urachal fistula [6-8]. Diagnosis depends upon the clinical and radiological assessment and confirmed at surgery. Palin X-ray is the first modality of choice, then contrast study to determine the exact site of the fistula. Abdominal ultrasonography is done as a routine examination to detect associated congenital anomalies [9-12].

The aim of this work is to illustrate the spectrum of neonatal fistula founded in routine neonatal radiology workup with clinical and surgical correlation. 
Table 1 Types, numbers, and radiological and surgical data of neonatal and infantile fistulas

\begin{tabular}{|c|c|c|c|}
\hline Type of fistula & Number (34) & Radiology & Treatment \\
\hline Branchial & 1 & Blind tract with a distal small cavity & Fistulectomy \\
\hline Thyroglossal & 2 & $\begin{array}{l}\text { A fistulous tract ending at the base } \\
\text { of the tongue }\end{array}$ & Fistulectomy \\
\hline Tracheo-esophageal (distal) & 6 & $\begin{array}{l}\text { Esophageal atresia with gastric and } \\
\text { intestinal gases }\end{array}$ & $\begin{array}{l}\text { Surgical repair of atresia and ligation } \\
\text { of the fistula }\end{array}$ \\
\hline Tracheo-esophageal (proximal) & 1 & Esophageal atresia with gasless abdomen & $\begin{array}{l}\text { Surgical repair of atresia and ligation } \\
\text { of the fistula }\end{array}$ \\
\hline Tracheo-esophageal (H shape) & 1 & A tract between the esophagus and trachea & Ligation of the fistula \\
\hline Esophago-cutaneous (iatrogenic) & 1 & $\begin{array}{l}\text { A fistulous tract between the esophagus } \\
\text { and skin after esophageal atresia repair }\end{array}$ & Ryle tube insertion \\
\hline Esophago-pleural (iatrogenic) & 1 & $\begin{array}{l}\text { A fistulous tract between the esophagus } \\
\text { and plural after Ryle tube maneuvering }\end{array}$ & Ryle tube insertion \\
\hline Vitello-intestinal & 3 & $\begin{array}{l}\text { A fistulous tract between the umbilicus } \\
\text { and small intestine }\end{array}$ & Surgical excision of the fistulous tract \\
\hline Urachal & 1 & $\begin{array}{l}\text { A fistulous tract between the umbilicus } \\
\text { and urinary bladder }\end{array}$ & Surgical excision of the fistulous tract \\
\hline Recto-vesical & 1 & $\begin{array}{l}\text { A fistulous tract between the rectal pouch } \\
\text { and urinary bladder }\end{array}$ & $\begin{array}{l}\text { Surgical repair during second-stage } \\
\text { treatment of imperforate anus }\end{array}$ \\
\hline Recto-urethral (prostatic) & 1 & $\begin{array}{l}\text { A fistulous tract between the rectal pouch } \\
\text { and posterior urethra }\end{array}$ & $\begin{array}{l}\text { Surgical repair during second-stage } \\
\text { treatment of imperforate anus }\end{array}$ \\
\hline Recto-urethral (bulbar) & 6 & $\begin{array}{l}\text { A fistulous tract between the rectal pouch } \\
\text { and membranous urethra }\end{array}$ & $\begin{array}{l}\text { Surgical repair during second-stage } \\
\text { treatment of imperforate anus }\end{array}$ \\
\hline Recto-urethral (distal urethra) & 1 & $\begin{array}{l}\text { A fistulous tract between the rectal pouch } \\
\text { and anterior urethra }\end{array}$ & $\begin{array}{l}\text { Surgical repair during second-stage } \\
\text { treatment of imperforate anus }\end{array}$ \\
\hline Recto-vaginal & 2 & $\begin{array}{l}\text { A fistulous tract between the rectal pouch } \\
\text { and vagina }\end{array}$ & $\begin{array}{l}\text { Surgical repair during second-stage } \\
\text { treatment of imperforate anus }\end{array}$ \\
\hline Recto-perineal & 1 & $\begin{array}{l}\text { A fistulous tract between the rectal pouch } \\
\text { and perineum with imperforate anus }\end{array}$ & $\begin{array}{l}\text { Surgical repair during second-stage } \\
\text { treatment of imperforate anus }\end{array}$ \\
\hline Peri-anal & 4 & $\begin{array}{l}\text { A fistulous tract between the rectal pouch } \\
\text { and perineum }\end{array}$ & Fistulectomy \\
\hline Urethro-perineal & 1 & $\begin{array}{l}\text { A fistulous tract between the urethra } \\
\text { and perineum }\end{array}$ & Surgical repair \\
\hline
\end{tabular}

\section{Material and methods}

Patients with neonatal fistula especially of gastro-intestinal (GIT) and urinary tract were included and retrospectively reviewed. All clinical, radiological, and surgical data of those patients were thoroughly investigated. The patients were referred to the Diagnostic Radiology Department at Sohag University Hospital and private sectors from December 2015 to February 2019. The exclusion criteria were patients with vascular fistula. The neonates presented with increase oral secretion, cyanosis on feeding, cutaneous discharge, or inability to pass meconium.

Meticulous care and warming were followed during handling to do a radiological examination. Those neonates were subjected at first to erect abdominal and chest X-ray. The GIT air in this X-ray was analyzed as regards the presence of proximal esophageal pouch with a coiled Ryle catheter, presence or absence of gastric and intestinal air, chest infection and air-fluid levels, air under the diaphragm, and associated skeletal and heart congenital anomalies.

The second examination was a contrast study. This technique was tailored according to the state of the patient. Contrast esophagogram was done to patients

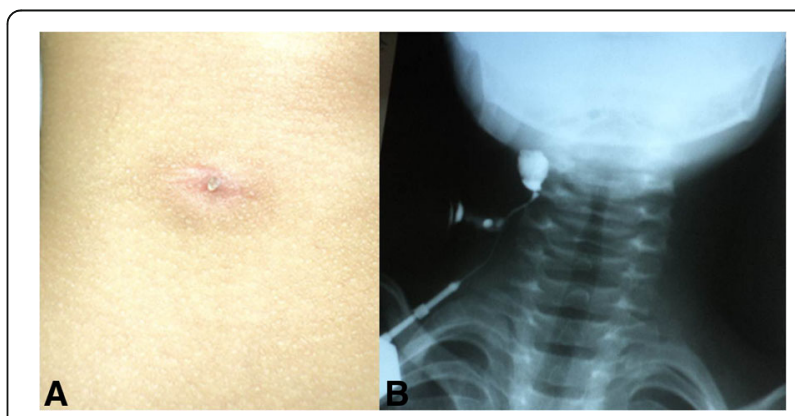

Fig. 1 Branchial fistula. a A photograph of the fistulous opening. b Fistulography; the image shows a tract in the right side of the neck with distal cavity 


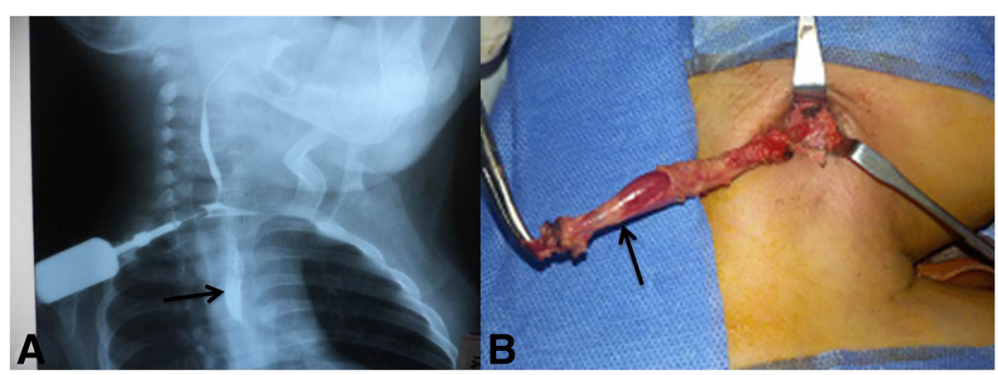

Fig. 2 Thyroglossal fistula. a Fistulography; the image shows a tract in the right side of the neck extending to the base of the tongue. Spill on contrast into the pharynx with esophageal opacification (arrow) is observed. b A photograph of the fistulous tract on surgery (arrow)

suspected to have tracheo-esophageal fistula. The technique was done by injection of minimal contrast (Ultravist; $1-2 \mathrm{~cm}$ ) in a Ryle catheter. Lateral or oblique view was taken from the patients to visualize any tracheo-esophageal fistula. As regards patients with ano-rectal malformations especially with imperforate anus, augmented pressure colostogram was done after colostomy. This was done by injection of $10-15 \mathrm{~cm}$ of saline diluted contrast (Ultravist) in a Foley catheter inserted in distal colostomy opening after balloon filling. Lateral view was done to detect any fistulous tract and detect its exact site of connection. Ascending and voiding urethrogram was also done to patients suspected of ano-rectal malformation fistula. Conventional fistulography was done to patient with cutaneous fistula, and appropriate filming was taken.

All neonates were subjected to routine abdominal ultrasonography to detect any associated abdominal congenital anomalies or any abdominal abnormalities such as fluid collection. All radiological examinations were done by one radiologist with 25 years of conventional radiology experience.

All neonates were operated upon in the Pediatric Surgery Unit at Sohag University Hospitals and private sectors. Final diagnosis was done at surgery and correlates with the radiological data. Highly qualified preoperative care was achieved in the intensive care unit.

\section{Results}

Our study included 34 patients (25 boys and 9 girls). Their age ranged from few hours to 3 years as shown in Table 1. All radiological findings correlated well with the surgical data with an accuracy of $100 \%$. This work included one case with branchial fistula. A fistulous tract was seen ascending from the lateral neck upwards with distal cavity (Fig. 1). There were also two cases with thyroglossal fistula. A long tract was illustrated on a conventional fistulogram with oro-pharangeal opacification, and even opacification of the esophagus is noted (Figs. 2 and 3). These cases were treated surgically by fistulectomy.

Eight cases were tracheo-esophageal fistula in this study. Tracheo-esophageal atresia with distal tracheoesophageal fistula was found in 6 neonates. On plain X-ray, dilated proximal esophageal pouch, coiled Ryle tube, and the presence of gastric and intestinal air were observed (Fig. 4). Over spill of contrast from the esophagus to trachea then to the fistula with distal esophagogram was observed in one newborn (Fig. 5). One case with proximal tracheo-esophageal fistula with gasless abdomen was encountered. Another case with H-type fistula was seen. All these cases were treated surgically by surgical repair and fistula ligation.

Esophago-cutaneous fistula was noted in one patient. This patient was operated previously to

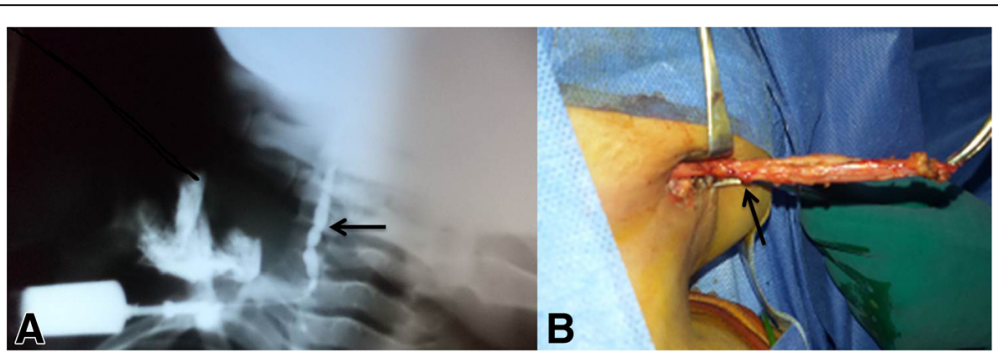

Fig. 3 Thyroglossal fistula. a Fistulography; the image illustrates a tract in the right side of the neck (arrow). b A photograph of the fistulous tract on surgery (arrow) 


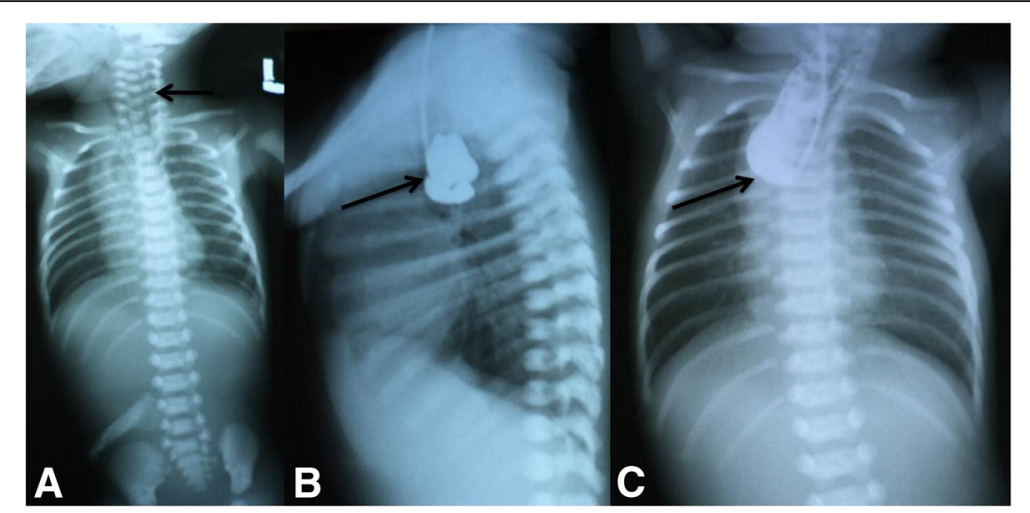

Fig. 4 Esophageal atresia without fistula in a neonate. a Plain X-ray demonstrating faint lucent pouch at the neck and upper chest (arrow) with gasless abdomen. $\mathbf{b}$ Lateral esophagogram shows the proximal esophageal pouch (arrow). c AP esophagogram well delineates the proximal esophageal pouch (arrow)

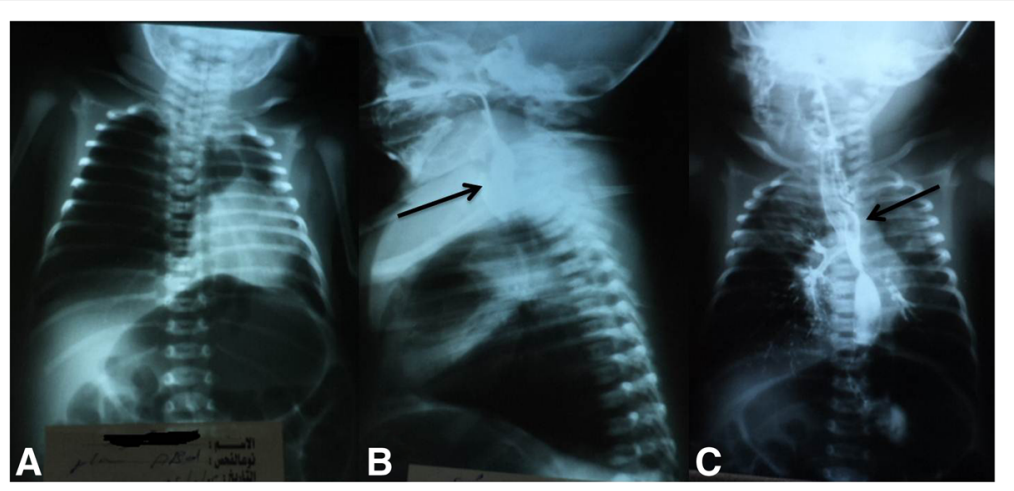

Fig. 5 Esophageal atresia with distal fistula in a neonate. a Plain X-ray shows a distended stomach with gases. b Lateral esophagogram illustrates the proximal esophageal pouch (arrow). c AP esophagogram accidentally detecting the fistula (arrow) with opacification of the distal esophagus (due to spill over of contrast to the trachea to the fistula then to the esophagus)

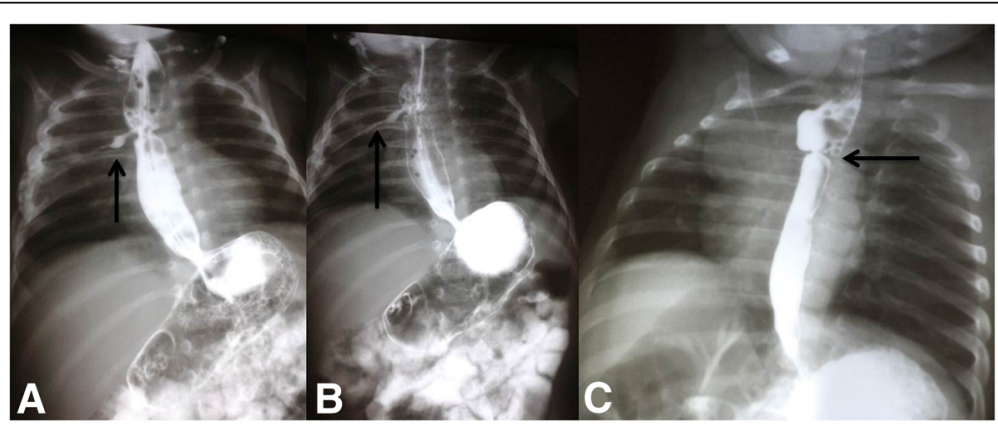

Fig. 6 Esophago-cutaneous fistula in a neonate after the repair of esophageal atresia. a, b Serial images of esophagogram showing the fistulous tract (arrows) and esophageal stricture. $\mathbf{c}$ Esophagogram after 1 month demonstrating occlusion of the fistula with persistence of the esophageal stricture (arrow) 


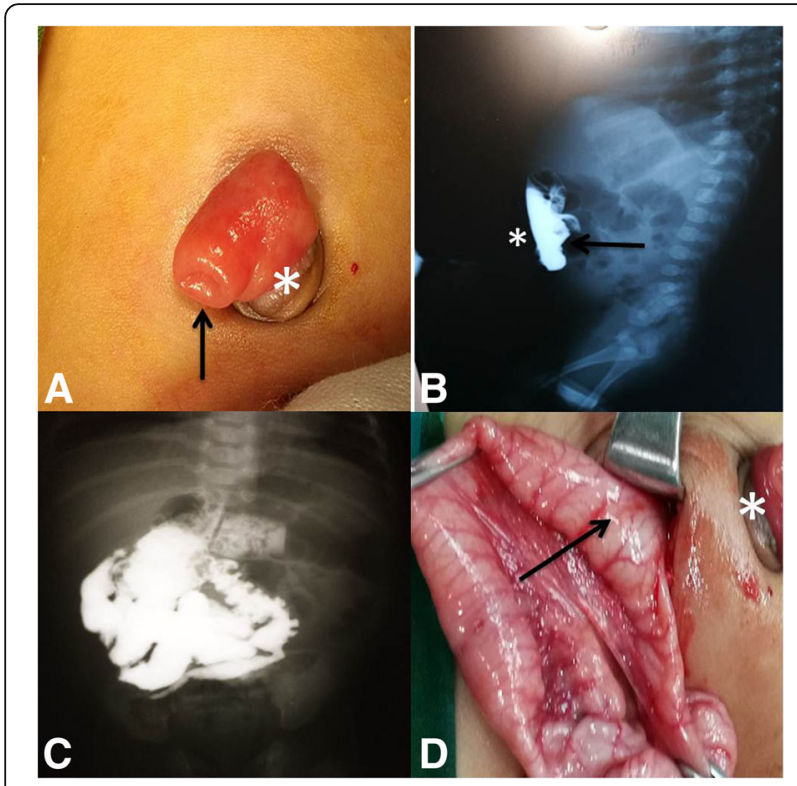

Fig. 7 An infant with vitello-intestinal fistula. a A photo showing the fistulous opening (arrow) at the umbilicus (*). b An initial fistulogram demonstrating the patent vitello-intestinal duct (arrow) behind the umbilicus (*). c The contrast image illustrates the opcified small intestinal loops distal to the patent vitello-intestinal duct. $\mathbf{d}$ Surgical image showing the site of the vitello-intestinal duct close to the umbilicus (*)

esophageal atresia with distal tracheo-esophageal fistula. The postoperative leakage was observed. A tract between the esophagus and skin was observed on esophagogram (Fig. 6). Another case of iatrogenic esophageal fistula was resulted after aggressive Ryle maneuvering with pleural fistula. These cases were treated by Ryle tube feeding for 3 weeks.

Three patients with vitello-intestinal fistula were seen. They presented with an umbilical discharge of fecal matter. On fistulogram, a tract is seen between the umbilicus and small intestine (Figs. 7 and 8). These findings were confirmed at the surgery with excision of the fistulous tract. Another case with an umbilical discharge of urine is demonstrated in our study. A fistulous tract is seen between the

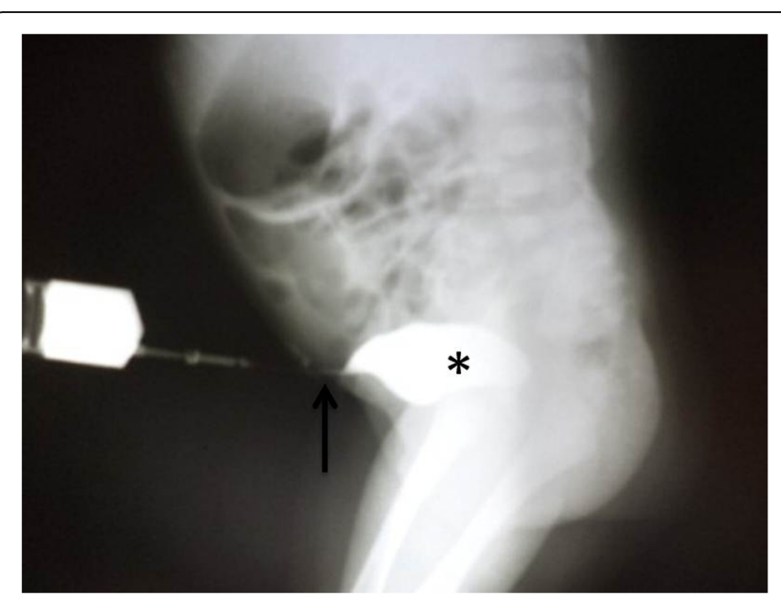

Fig. 9 Urachal fistula in an infant. Fistulogram image showing the fistulous tract (arrow) leading to the urinary bladder $(*)$

umbilicus and urinary bladder on fistulogram. The urachal fistula was treated with excision (Fig. 9).

Our study illustrated different types of rectal urinary fistula, especially at newborn with imperforate anus. They include one patient with a recto-vesical fistula (Fig. 10), one case with a recto-urethral fistula at the prostatic urethra (Fig. 11), 6 cases with a recto-urethral fistula at the bulbar urethra (Fig. 12), and one case with a recto-urethral fistula at the distal urethra (Fig. 13). These cases were treated surgically during second-stage repair of imperforate anus.

Two recto-vaginal fistulas were reported in our series with imperforate anus (Fig. 14). The rectoperineal fistula was also seen in one case with imperforate anus (Fig. 15). These fistulas appear on colostogram. Surgical repair was done during the second-stage treatment of imperforate anus.

Cloacal cystic lesion anomalies and vesico-ureteric reflux are associated with ano-rectal malformation in this study (Fig. 16). Cloacal anomalies were seen in our study in 2 cases and vesico-ureteric reflux in 3 cases (Fig. 17).

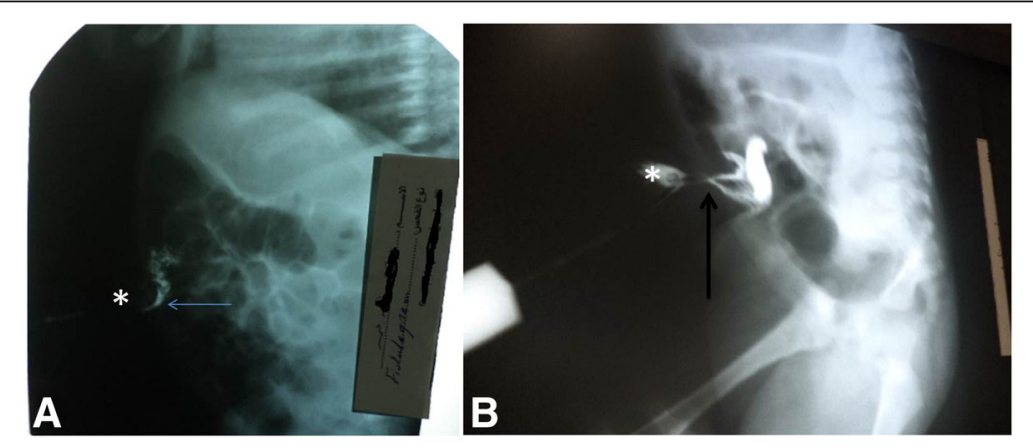

Fig. 8 Vitello-intestinal fistula in two infants. a, b Fistulogram images showing the fistulous tracts (arrows) behind the umbilicus (*) 


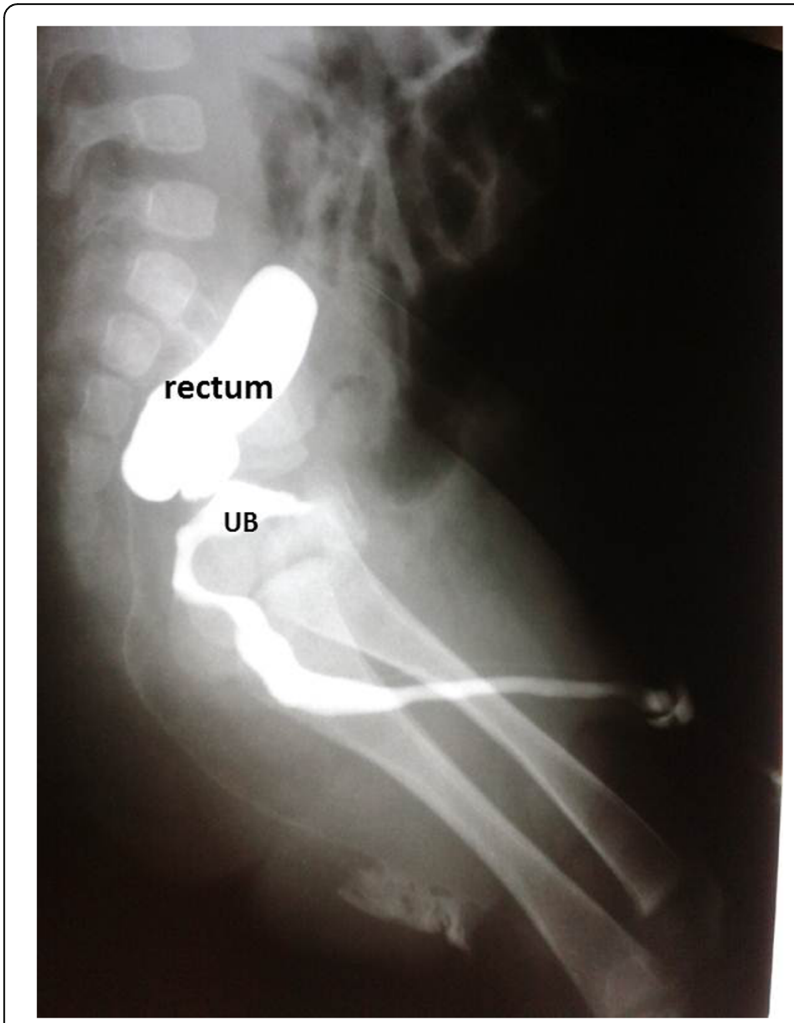

Fig. 10 Recto-vesical fistula in an infant. Voiding cysto-urethrogram showing the rectum could not be separated from the UB

Infantile peri-anal fistula was observed in 4 cases in our work (Fig. 18). They were acquired and low fistula. They were well demonstrated on the perianal fistulogram. They were treated by fistulectomy. The last case was acquired distal infantile urethracutaneous fistula. This fistula was illustrated obviously on ascending urethrography (Fig. 19). It is treated by a surgical repair.

Postoperative care was done in an intensive care unit. Body temperature and fluid are especially having the upper hand of care.

\section{Discussion}

Fistulas at neonatal and infantile period are frequently encountered at this age group. Our study included 34 cases of neonatal and infantile fistula. To our knowledge, no previous literature reported a diverse collection of neonatal and infantile fistula. Most of the reported literatures concentrated upon a single type of them [13-15]. GIT and urinary fistulas are the most common fistulas enrolled in this series.

Tracheo-esophageal fistulas (distal, proximal, or $\mathrm{H}$ shape) were found in our study in 8 cases. These results were seen in another report [16]. Esophageal atresia with distal tracheo-esophageal fistula was the most common type. Iatrogenic esophago-cutaneous fistula or esophago-pleural fistula was encountered in 2 cases in our study. Esophago-cutaneous fistula may occur after the repair of esophageal atresia as a leakage at the site of incision. This complication was reported in another German report covering a big population [17]. Esophago-pleural fistula is reported in 2 cases in pediatric age group [18].

Branchial fistula was seen in one case in our work. On fistulogram, the tract ended in a cavity. Two cases of infantile thyroglossal fistula were found in our study. These fistulas were observed in other studies $[19,20]$.

Vitello-intestinal fistula is a non-atretic congenital duct between the umbilicus and the small intestine. It was found in 3 cases in this work. It was reported in many literatures [21]. Urachal fistula is a patent urachus with dripping of urine from the umbilicus. It was found in one case in our series. It was reported in other literatures $[22,23]$.

Ano-rectal malformations are frequently associated with neonatal fistula especially with imperforate anus. Congenital neonatal recto-urinary fistulas were found in 9 cases in our study. It may be recto-vesical (one case), recto-urethral at the prostatic level (one case), recto-urethral at the bulbar level (6cases), and recto-urethral at the distal urethra (one case). Moreover, congenital recto-vaginal (one case) and recto-cutaneous (one case) fistulas were also observed in this work. Augmented pressure colostogram and/or voiding cysto-urethrogram had delineated the fistulous tract well. Karsten et al. [24] reported 16 recto-urethral fistulas and 4 cases with recto-vesical fistula by using the voiding cystourethrogram. Thomeer et al. [25] examine neonates with

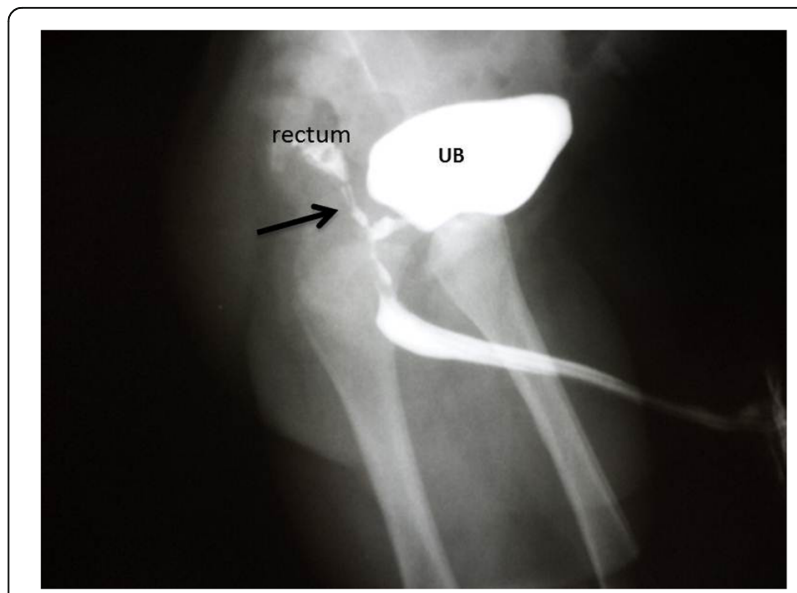

Fig. 11 Recto-urethral (prostatic) fistula in an infant. Ascending cysto-urethrogram showing the fistulous tract (arrow) between the rectum and the prostatic urethra 


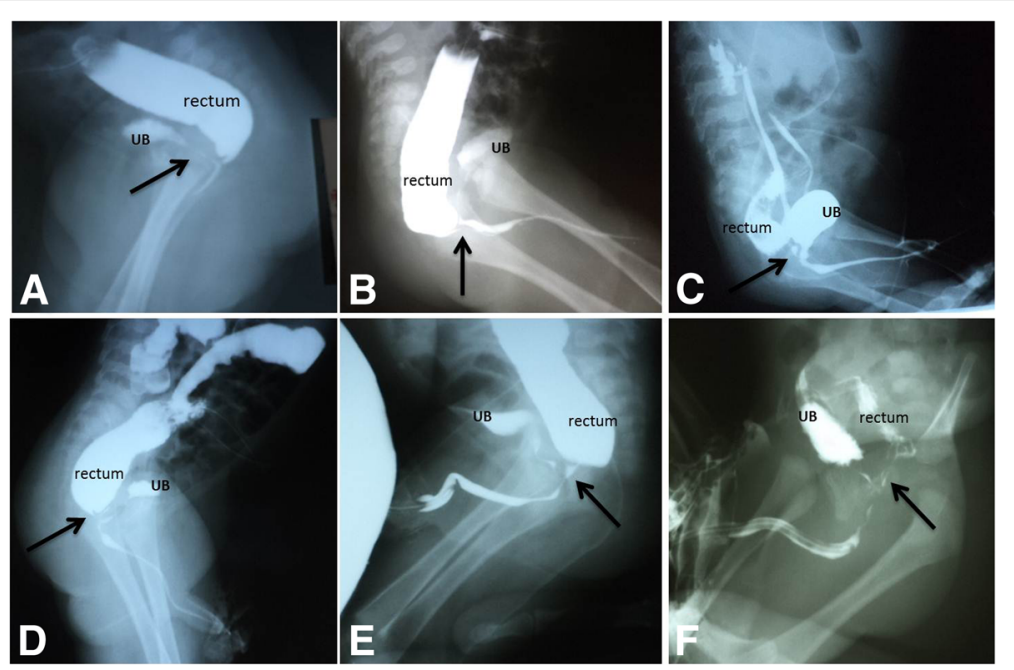

Fig. 12 Recto-urethral (bulbar) fistula. a-f Contrast images showing the fistulous tracts (arrows) between the rectum and the bulbar urethra in 6 different cases

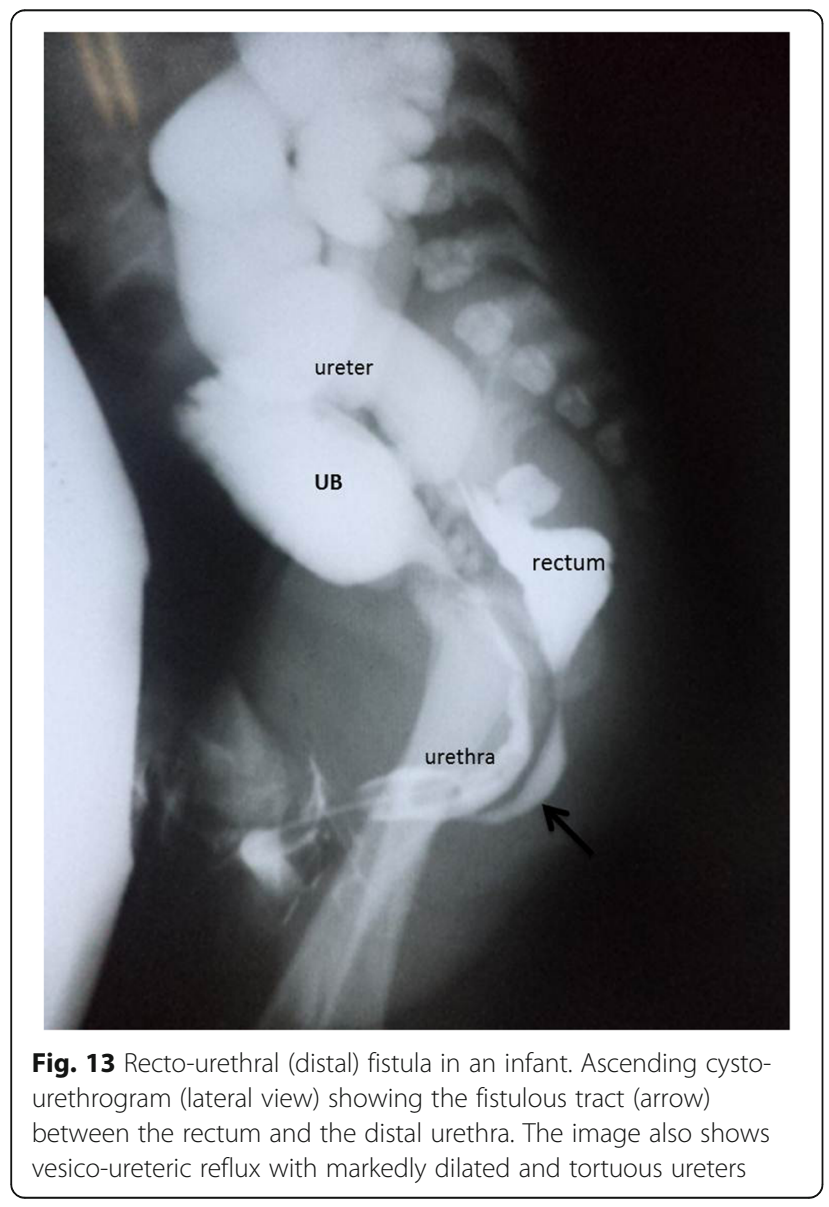

ano-rectal malformations, and they found 9 cases with recto-bulbar urethral fistula, 6 cases with recto-prostatic urethral fistula, one case with bladder neck fistula, and one neonate with recto-perineal.

Cloacal cystic anomalies were associated with anorectal malformations in our study in 2 cases [26, 27]. Vesico-ureteric reflux was found in 3 cases. Cloacal anomalies and vesico-ureteric reflux are frequently associated with ano-rectal malformations [26-28]. Acquired perineal fistula was reported in 4 cases in this study. Usually, perineal fistula presented in the older age group after perineal suppuration. All perineal fistulas were low and treated by fistulectomy as seen in the literature [29].

This work included another case of iatrogenic infantile fistula which is urethro-cutaneous fistula. Iatrogenic urethro-cutaneous fistulas were reported as congenital fistula [30] or as a complication after the repair of hypospadias [31].

This study has limitations in the form of a small number of patients, not including other fistulas such as GIT or vascular fistula, and only conventional Xray and fistulogram are used, not computed tomography (CT) nor magnetic resonance (MR).

\section{Conclusion}

This study illustrated the radiological spectrum of different types of neonatal and infantile fistula on conventional contrast imaging with surgical correlation. Our work included branchial, thyroglossal, tracheo-esophageal, recto-urinary, vitello-intestinal, urachal, and few iatrogenic neonatal and infantile fistulas. Further studies on a large number of patients and other imaging modalities including CT and MRI are recommended. 


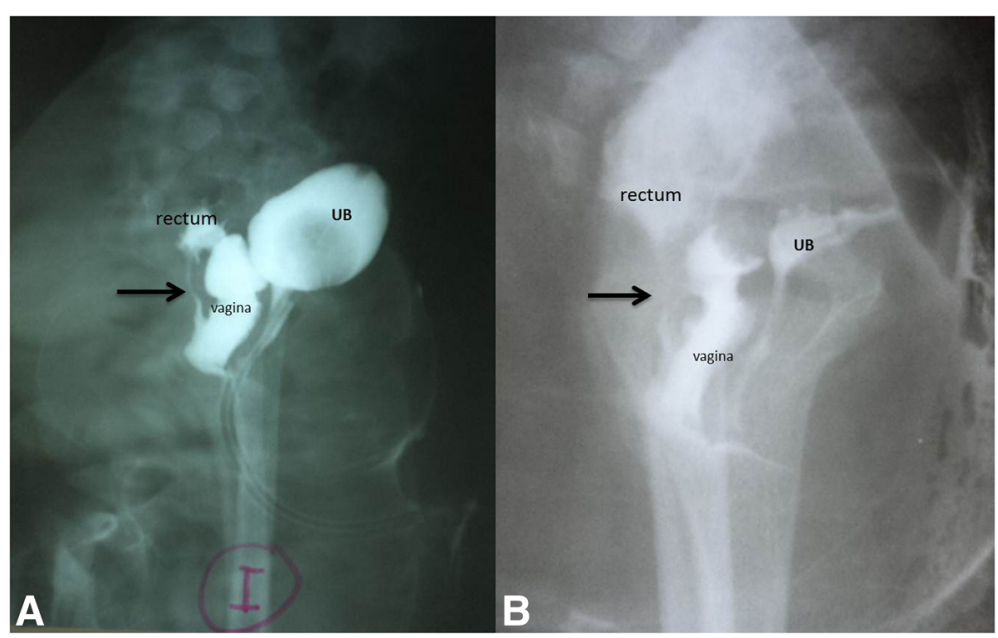

Fig. 14 Recto-vaginal fistula in an infant. a, b Ascending and voiding cysto-urethrogram images showing the fistulous tract (arrows) between the rectum and the vagina

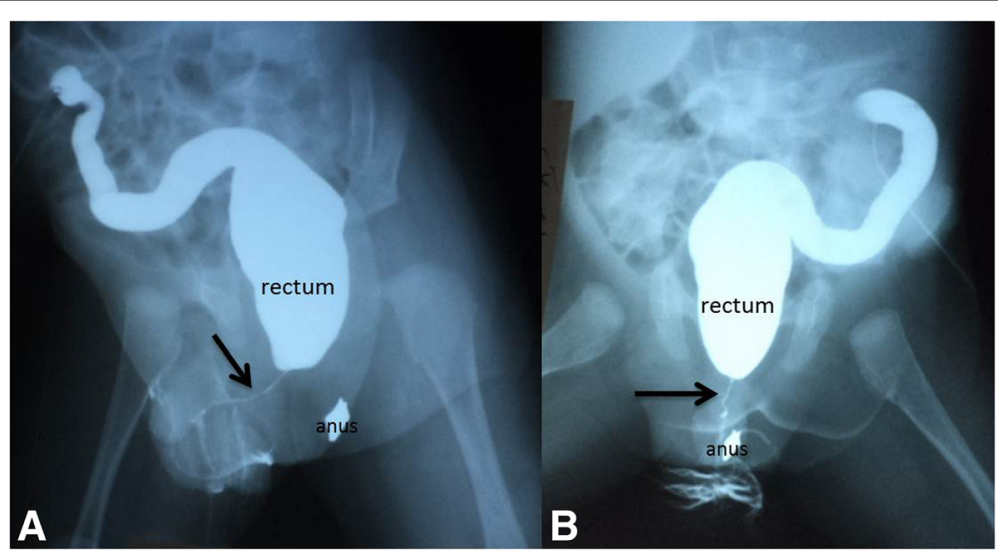

Fig. 15 Recto-perineal fistula in an infant. a, b AP and oblique colostogram images showing the fistulous tract (arrow) between the rectum and the perineum. The mark denoting the anus

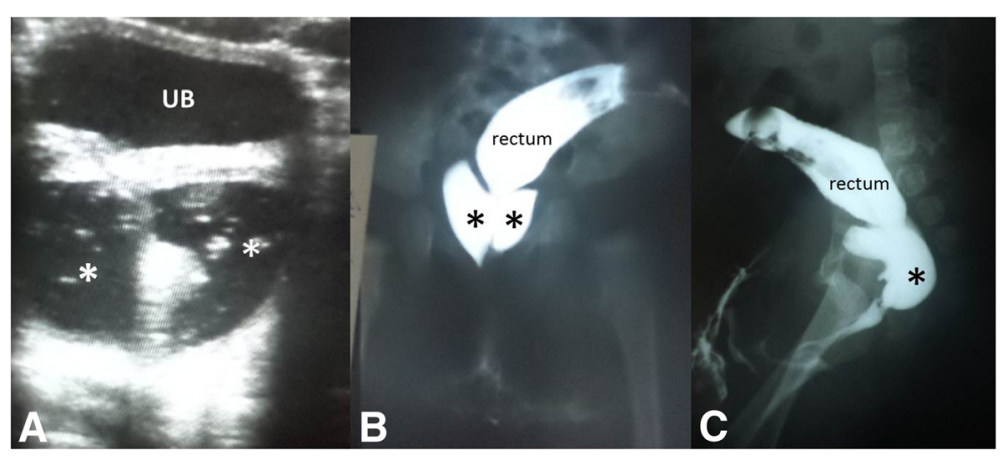

Fig. 16 Cloacal anomalies in a neonate. a US image illustrating two cystic lesions (*) behind the urinary bladder (UB). b, c AP and lateral colostogram images showing the rectum and cloacal cystic lesions (*) 


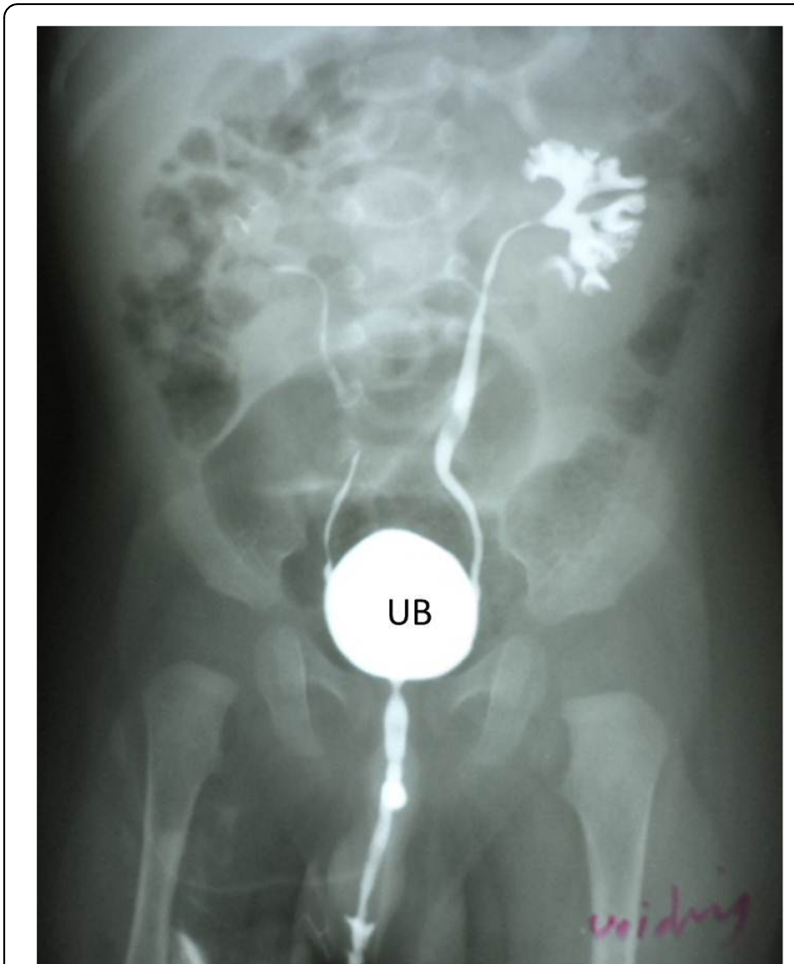

Fig. 17 Vesico-ureteric reflux in a neonate. A voiding cysto-urethrogram image showing bilateral vesico-ureteric reflux, more on the left side

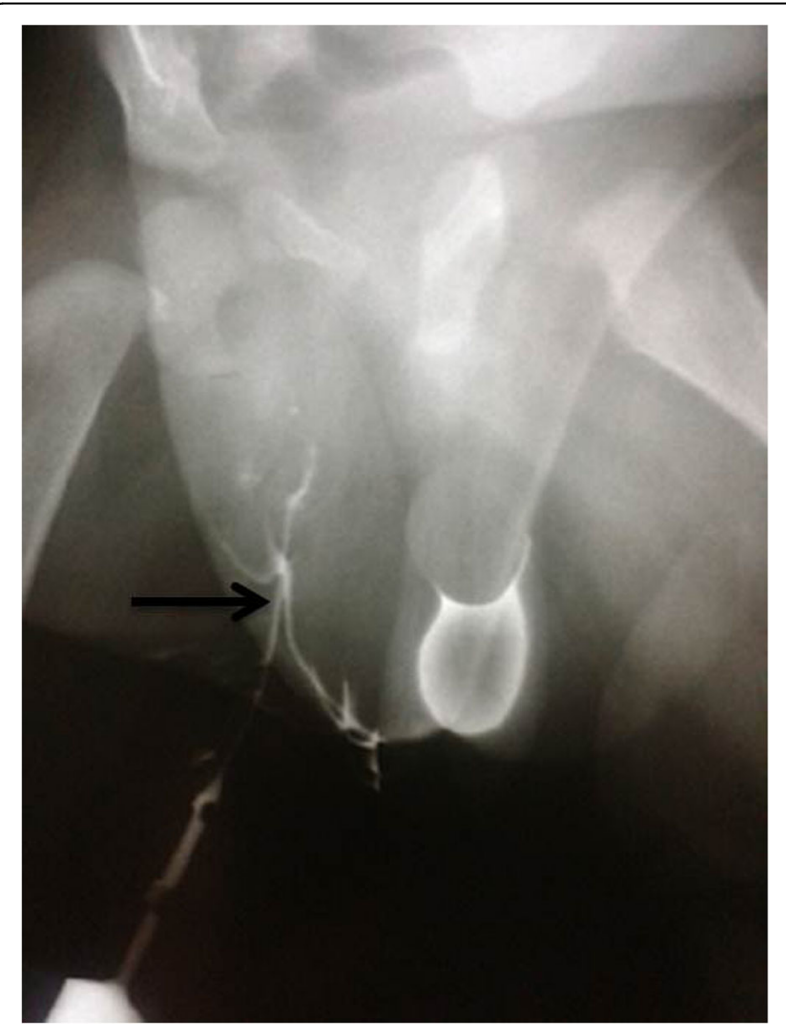

Fig. 18 Peri-anal fistula in an infant. Peri-anal fistulogram showing the short fistulous tract

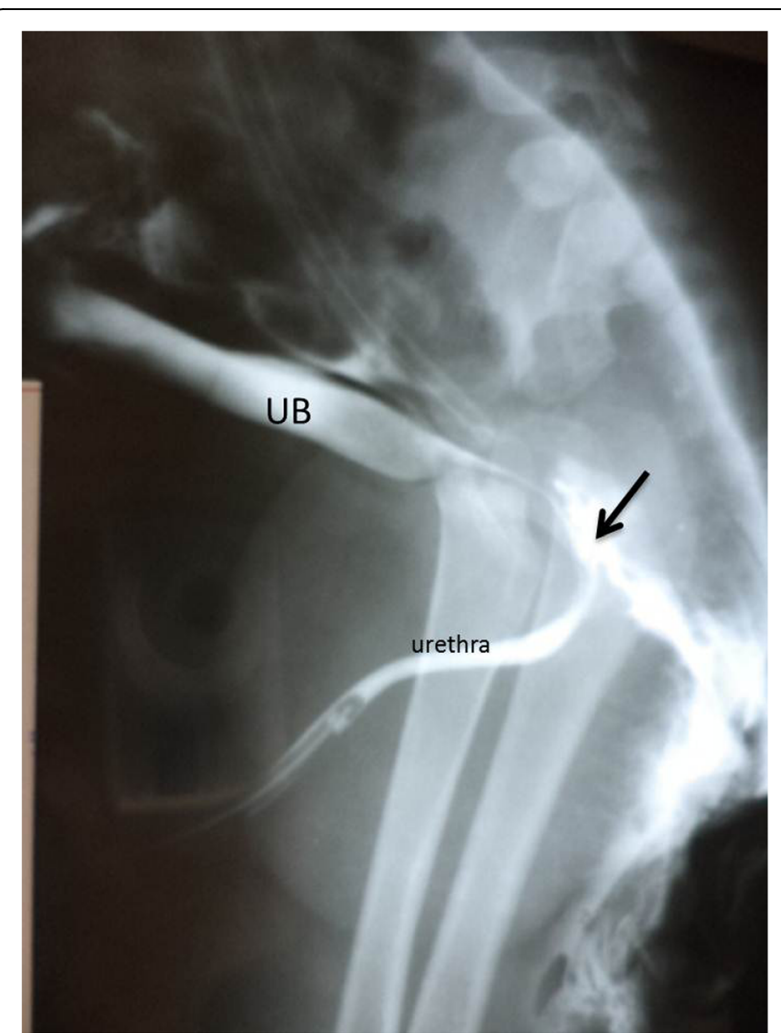

Fig. 19 latrogenic urethro-cutaneous fistula in an infant. Ascending cysto-urethrogram showing leakage of contrast at the site of the bulbar urethra

\section{Abbreviations}

GIT: Gastro-intestinal tract; CT: Computed tomography; MR: Magnetic resonance

\section{Acknowledgements}

Not applicable

\section{Authors' contributions}

The two authors cooperate in the manuscript writing and design. ZM carried out the radiological examinations. BMY carried out the surgical maneuvers. The two authors read and approved the final manuscript. ZM submitted the manuscript.

\section{Funding}

Not applicable

\section{Availability of data and materials}

The datasets used and/or analyzed during the current study are available from the corresponding author.

\section{Ethics approval and consent to participate}

The current study was approved by our Institutional Committee in Sohag University Faculty of Medicine. Written informed consent was obtained from all patients and volunteers.

\section{Consent for publication}

Ethically, oral and written informed consent was taken from the patients' parents or the guardian in accord with the ethical standards of the institutional committee.

\section{Competing interests}

The authors declare that they have no competing interests. 


\section{Author details}

'Department of Radiology, Sohag Faculty of Medicine, Sohag University, Sohag, Egypt. ${ }^{2}$ Pediatric Surgery Unit, Department of Surgery, Sohag Faculty of Medicine, Sohag University, Sohag, Egypt.

Received: 4 June 2019 Accepted: 4 July 2019

Published online: 02 September 2019

\section{References}

1. Trobs RB, Finke W, Bahr M et al (2017) Isolated tracheoesophageal fistula versus esophageal atresia-early morbidity and short-term outcome. A single institution series. Int J Pediatr Otorhinolaryngol 94:104-111

2. Currarino G (1996) The various types of anorectal fistula in male imperforate anus. Pediatr Radiol 26(8):512-522

3. Handa N (2016) Vitellointestinal fistula and urachal remnant. In: Taguchi T, Iwanaka T, Okamatsu T (eds) Operative general surgery in neonates and infants. Springer, Tokyo, pp 163-168

4. Hager J, Gassner I (1994) Gastrocolic fistula in a 7 week old: a rare complication after gastric perforation. J Pediatr Surg 29(12):1597-1598

5. Andrew M, Lewis M, Aquino NM (1992) Congenital portohepatic vein fistula that resolved spontaneously in a neonate. AJR 159:837-838

6. Kovesi T, Steven Rubin S (2004) Long-term complications of congenital esophageal atresia and/or tracheoesophageal fistula. Chest J 126(3):915-925

7. Keily EM, Peña A. Imperforate anus. In: O'Neill JA Jr, Rowe MI, Grosfeld JL, Fonkalsrud EW, Coran AG, eds. Pediatric Surgery. 5th ed. St Louis, MO: Mosby Yearbook; 1998:1425-1448.

8. Isaacs GS, Singh B (2010) The micturating umbilicus. SAMJ 100(1):22-23

9. Beasley SW, SW MNA (1988) The diagnosis of congenital tracheoesophageal fistula. J Pediatr Surg 23(5):415-417

10. Gross GW, Wolfson PJ, Pena A (1991) Augmented-pressure colostogram in imperforate anus with fistula. Pediatr Radiol 21(8):560-562

11. Choi YH, Kim IO, Cheon JE, Kim WS, Yeon KM (2009) Imperforate anus: determination of type using transperineal ultrasonography. Korean J Radiol 10:355-360

12. Abdulkadir AY, Abdur-Rahman LO, Adesiyun OM (2009) Nonfluoroscopic pressure colostography in the evaluation of genitourinary fistula of anorectal malformations: experience in a resource-poor environment. Pediatr Radiol 39(2):132-136

13. Choi YJ, Kim JM, Ahn SY, Oh J-T, Han SW, Lee JS (2006) Urachal anomalies in children: a single center experience. Yonsei Med J 47(6):782-786

14. Ciongradi I, Aprodu G, Olaru C et al (2016) Anorectal malformations in a tertiary pediatric surgery center from Romania: 20 years of experience. $J$ Surg 12(2):55-59

15. Kavalcova L, Skaba R, KynclM RB, Prochazka A (2013) The diagnostic value of MRI fistulogram and MRI distal colostogram in patients with anorectal malformations. J Pediatr Surg 48:1806-1809

16. Hamad NA, Kak-Ahmed HA, Allaquli NI (2018) Early outcome of surgical intervention of esophageal atresia and tracheo-esophageal fistula in Erbil Pediatric Surgical Center. Med J Babylon 5(2):129-134

17. Dingemann C, Dietrich J, Zeidler J et al (2016) Early complications after esophageal atresia repair: analysis of a German health insurance database covering a population of 8 million. Dis Esophagus 29(7):780-786

18. Cui Y, Ren Y, Shan Y et al (2017) Pediatric esophagopleural fistula: two case reports and a literature review. Med (Baltimore) 96(19):e6695

19. Sahu S, Kumar A, Ramakrishnan TS (2011) Branchial fistula: an imaging perspective. Med J Armed Forces India. 67(3):262-264

20. Alnaimy T, Sieda BM, Baiomy T (2016) Thyroglossal cyst and fistula: surgical pitfalls and causes of recurrence. Egypt J Surg 35(1):49-53

21. Kadian YS, Verma A, Rattan KN, Kajal P (2016) Vitellointestinal duct anomalies in infancy. J Neonatal Surg 5(3):30

22. Sisodiya N, Shukla RM, Mukhopadhyay B, Mandal KC (2015) Patent urachus in a neonate: a rarity. Indian J Surg 77(Suppl2):722-723

23. Keshava Murthy M, Naveen S, Hanumanthaiah AE, Sunil B (2014) Patent urachus in a neonate presenting with severe umbilical bleeding: a case report. JIMSA 27(1):27

24. Karsten K, Rothe K, Märzheuser S (2016) Voiding cystourethrography in the diagnosis of anorectal malformations. Eur J Pediatr Surg 26(6):494-499

25. Thomeer MG, Devos A, Lequin M et al (2015) High resolution MRI for preoperative work-up of neonates with an anorectal malformation: a direct comparison with distal pressure colostography/fistulography. Eur Radiol 25:3472-3479

26. Rios LT, Araujo Júnior E, Nardozza LM et al (2012) Prenatal diagnosis and postnatal ultrasound findings of cloacal anomaly: a case report. Case Rep Pediatr. 2012:969860

27. Winkler NS, Kennedy AM, Woodward PJ (2012) Cloacal malformation: embryology, anatomy, and prenatal imaging features. J Ultrasound Med 31: 1843-1855

28. Sanchez S, Ricca R, Joyner B, Waldhausen JHT (2014) Vesicoureteral reflux and febrile urinary tract infections in anorectal malformations: a retrospective review. Journal of Pediatric Surgery 49(1):91-94

29. Ali Gafar AMA (2013) Fistulotomy versus fistulectomy as a treatment for low anal fistula in infants: a comparative study. Annals of Pediatric Surgery 9(3):103-107

30. Bhatnagar A, Upadhyaya VD, Kumar B (2012) Congenital urethrocutaneous fistula: case report with review of literature. Indian J Plast Surg. 45(3):563-565

31. Agrawal K, Misra A (2013) Unfavourable results in hypospadias. Indian J Plast Surg. 46(2):419-427

\section{Publisher's Note}

Springer Nature remains neutral with regard to jurisdictional claims in published maps and institutional affiliations.

\section{Submit your manuscript to a SpringerOpen ${ }^{\circ}$ journal and benefit from:}

- Convenient online submission

Rigorous peer review

- Open access: articles freely available online

- High visibility within the field

- Retaining the copyright to your article

Submit your next manuscript at $\boldsymbol{\nabla}$ springeropen.com 